\title{
Influence of the presence of medium-soft paraffin wax on the morphology and properties of iPP/silver nanocomposites
}

\author{
M. P. Molaba ${ }^{1}$, D. Dudić ${ }^{1,2}$, A. S. Luyt $t^{1,3^{*}}$ \\ ${ }^{1}$ Department of Chemistry, University of the Free State, Private Bag X13, 9866 Phuthaditjhaba, South Africa \\ ${ }^{2}$ Vinča Institute of Nuclear Sciences, University of Belgrade, P.O. Box 522, 11001 Belgrade, Serbia \\ ${ }^{3}$ Current address: Center for Advanced Materials, Qatar University, PO Box 2713, Doha, Qatar
}

Received 15 March 2015; accepted in revised form 17 May 2015

\begin{abstract}
The aim of this study was to investigate the presence of wax, different Ag nanoparticle contents, and different cooling rates from the melt, on the morphology, thermal and electrical conductivity, and dynamic mechanical properties of iPP. The Ag particles were well dispersed in the polymer, and formed nucleation centres for the crystallization of iPP. They were also well dispersed in iPP/wax, but they were located in the wax phase which was dispersed between the iPP spherulites. Generally the extent of filler agglomeration increased with increasing filler content. The Ag particles, whether in the iPP or wax phase, had little influence on the crystallinities and melting temperatures of iPP. The presence of Ag particles in iPP had little influence on its modulus, but the presence of both wax and Ag particles significantly improved the modulus of these nanocomposites. The thermal and electrical conductivities of the samples more significantly improved when both wax and Ag were present. With increasing $\mathrm{Ag}$ particle contents in both $\mathrm{iPP} / \mathrm{Ag}$ and iPP/wax/Ag, the thermal conductivities increased, but leveled off at higher filler contents, while the electrical conductivities continuously increased with increasing filler contents. The slowly cooled samples had higher crystallinities than the quenched samples and therefore they were more thermally conductive than the quenched samples.
\end{abstract}

Keywords: nanocomposites, isotactic polypropylene, paraffin wax, morphology, conductivity

\section{Introduction}

Paraffin waxes can be used as organic phase-change materials (PCM) for thermal energy storage. This is because they are more chemically stable than inorganic substances, have a high latent heat of fusion, are commercially available at a reasonable cost, and exhibit little or no supercooling [1-3]. However, when used as PCMs, paraffin waxes need a supporting material to prevent their leakage during the phase-change process. Blending of PCMs with polyolefins has been commonly used as a method of preventing the leakage of phase-change materials. In blending, the polymer fixes the PCM in a compact shape during the phase-change process, and hence prevents leakage [4].
However, if polyolefins are used as the fixing polymers, both the polymer and the paraffin wax have low thermal conductivity which results in a slow heat transfer $[5,6]$. The introduction of conductive nano-fillers has been used as a method for improving the thermal conductivity of PCMs. This is because they offer improved properties at relatively low filler content due to their larger surface areas [7]. These nano-fillers include aluminum, silver, copper, graphite and carbon black [8]. For this work we chose silver because it has very good electrical and thermal conductivies [9].

The morphology, as well as thermal and thermomechanical properties, of polyethylene (PE)/wax/wood flour composites were investigated in a few studies

\footnotetext{
${ }^{*}$ Corresponding author, e-mail: aluyt@qu.edu.qa

(C) BME-PT
} 
[10-12]. Generally the authors observed two phase morphologies with the filler covered by wax. These studies reported two endothermic peaks for the composites related to the melting of the wax and the polymer. It was found that the presence, type and amount of the filler particles did not change the melting behaviour of PE or wax in the composites. A limited amount of research has been done on the dynamic mechanical properties of polymer/wax blend composites $[11,13]$. When expanded graphite was used as filler, an increase in storage modulus was observed with an increase in filler content, which was an indication that the filler reinforced the matrix and countered the softening effect of the wax [13]. No specific trends related to the amount of filler particles were observed. However, the presence of wood filler particles in the polymer/wax blends reduced the storage modulus [11].

The thermal conductivity of form-stable PCM composites was investigated in a number of studies [5, 12-15]. An increase in the thermal conductivity of the composites with increasing filler content was observed, as well as the formation of thermally conductive paths. However, one of the papers [12] reported an initial decrease in thermal conductivity at low filler contents, which increased at higher filler loadings. This was attributed to the voids that formed at the interface between the polymer and the wax.

In this paper we report on the dispersion of Ag particles in iPP and an iPP/wax blend and the influence of quenching and slow cooling treatments on the morphology, thermal and dynamic mechanical properties, as well as thermal and electrical conductivities, in order to obtain more information on how the presence of wax, as well as different thermal treatments, will influence the morphology and related thermal, mechanical and conductivity properties of isotactic polypropylene.

\section{Materials and methods}

\subsection{Materials}

Isotactic polypropylene with a melt flow index of $12 \mathrm{~g} / 10 \mathrm{~min}\left(230^{\circ} \mathrm{C} / 2.16 \mathrm{~kg}\right)$, density of $0.9 \mathrm{~g} \cdot \mathrm{cm}^{-3}$ and melting point of $\sim 160^{\circ} \mathrm{C}$ was supplied by Sasol Polymers in South Africa. Medium-soft paraffin wax (M3 wax) was supplied in powder form by Sasol Wax in South Africa. It consists of approximately $99 \%$ of straight chain hydrocarbons with a few branched chains. It has an average molar mass of
$440 \mathrm{~g} \cdot \mathrm{mol}^{-1}$ and a carbon distribution between $\mathrm{C} 15$ and $\mathrm{C} 78$. Its density is $0.90 \mathrm{~g} \cdot \mathrm{cm}^{-3}$ and it has a melting point range around $40-60^{\circ} \mathrm{C}$. The $99.99 \%$ pure silver (Ag) nanoparticles with particle size $30-50 \mathrm{~nm}$ was supplied by Dong Yang (HK) Int'l Group Ltd in China.

\subsection{Composite preparation}

All the samples were prepared by melt mixing using a Brabender Plastograph with a $55 \mathrm{~mL}$ internal mixer. The samples were mixed for $15 \mathrm{~min}$ at $190^{\circ} \mathrm{C}$ and $50 \mathrm{rpm}$. The dry Ag powder was ultra-sonicated for 6 hours prior to the sample preparation. For the blends, the components were premixed and then fed into the heated mixer, whereas for the composites the $\mathrm{Ag}$ nanoparticles were added into the Brabender mixer 5 minutes after premixing the $\mathrm{iPP} /$ wax blends. The samples were then melt pressed at $190^{\circ} \mathrm{C}$ for 5 minutes under $50 \mathrm{kPa}$ using a hydraulic melt press. The prepared samples were then exposed to two thermal treatments, either quenching in ice water or slow cooling from the melt at $190^{\circ} \mathrm{C}$ to a temperature of $100^{\circ} \mathrm{C}$.

\subsection{Characterization techniques}

For transmission electron microscopy (TEM) analysis the samples were sectioned at $150 \mathrm{~nm}$ using a Leica UC7 (Viennna, Austria) ultramicrotome, and examined with a Philips (FEI) (Eindhoven, The Netherlands) CM 100 transmission electron microscope at $60 \mathrm{keV}$.

The DSC analyses were done using a Perkin-Elmer DSC 7 differential scanning calorimeter under a nitrogen flow of $20 \mathrm{~mL} \cdot \mathrm{min}^{-1}$. Samples with masses of 5-10 $\mathrm{mg}$ in aluminium pans were heated from 20 to $180^{\circ} \mathrm{C}$ at $20^{\circ} \mathrm{C} \cdot \mathrm{min}^{-1}$, and cooled at the same rate. The peak temperatures of melting and crystallization, as well as the melting and crystallization enthalpies, were determined from the first heating and the cooling scans. Three samples of each composition were analysed, and the melting and crystallization values are reported as averages with standard deviations. The dynamic mechanical properties of the samples were investigated using a Perkin Elmer Diamond DMA. The analyses were performed from -40 to $140^{\circ} \mathrm{C}$ in bending (dual cantilever) mode at a heating rate of $3^{\circ} \mathrm{C} \cdot \mathrm{min}^{-1}$ and a frequency of $1 \mathrm{~Hz}$.

The thermal conductivities were measured using a Therm Test Inc. Hot Disk TPS 500 thermal constant analyzer. The hot disk sensor used in this study was 
a Kapton sensor with a radius of $3.2 \mathrm{~mm}$ and samples with $10 \mathrm{~mm}$ thickness and a diameter of $13 \mathrm{~mm}$ were used for the analyses. The sensor was placed between two samples of the same composition. The measurements were done for $20 \mathrm{~s}$ in order to prevent the heat flow from reaching the boundary of the samples. All the measurements were repeated ten times for each sample. The thermal conductivities are reported as average values with standard deviations.

For the dielectric measurements the samples were cut from the centre of the melt-pressed sheets in the form of discs $(D=13 \mathrm{~mm}, d=1 \mathrm{~mm})$. The surfaces of the samples were made conductive using soft graphite. Dielectric measurements were done using Agilent 4263B and Agilent 4285A dielectric spectroscopy instruments in the frequency range between $1 \mathrm{kHz}$ and $17 \mathrm{MHz}$ at room temperature, and with an applied voltage of $1 \mathrm{~V}$. Conductance $(G)$ and susceptance $(B)$ were measured using the $C p$ mode of the instrument, and the admittance $(Y)$ was calculated as $Y=\sqrt{B^{2}+G^{2}}$. The following relations were derived: $\tan \delta=G / B$ and $B=2 \pi f C$, where $f$ is the frequency and $C$ is the capacitance, and $C=\varepsilon^{\prime} \varepsilon_{0} S / d$, where $\varepsilon^{\prime}$ is the real part of the dielectric permittivity, $\varepsilon_{0}$ the vacuum permittivity and $S / d$ describing the geometry of the samples $\left(S=\pi D^{2} / 4\right)$. $D C$ measurements were done using a Keithley 2401 amperometer during $10 \mathrm{~s}$ of electric field application at $200 \mathrm{~V} \cdot \mathrm{mm}^{-1}$. All the electrical conductivities $\left(\sigma_{\mathrm{DC}}\right.$, $Y, G$ and $B)$ are presented as their specific values calculated as $\sigma=\sigma_{\text {measured }} d / S$, where $d / S$ is the geometry factor of the samples ( $S=$ surface area and $d=$ thickness).

\section{Results and discussion}

\subsection{Transmission electron microscopy (TEM)}

Figure 1 shows the TEM images of some of the investigated nanocomposites that were slowly cooled from the melt. The TEM image of the iPP/Ag nanocomposite containing $2 \mathrm{wt} \%$ nanoparticles shows iPP spherulites containing Ag nanoparticles at their growth centres (Figure 1a, arrow A). It looks as if primary nucleation could have started at the nanoparticles that formed nucleation centres from which the spherulitic growth evolved [16]. Ag nanoparticles and their agglomerates (with diameters ranging from 0.09 to $1.15 \mu \mathrm{m}$ ) can also be seen on the edges of the iPP spherulites, and they are fairly well dispersed. However, at a higher Ag content (Figure 1b) there are fewer individual $\mathrm{Ag}$ particles and more of the filler aggregates (with diameters ranging from 0.12 to $3.11 \mu \mathrm{m}$ ). The nanoparticles have a tendency of forming aggregates because they have a higher affinity for each other than for the matrix. The meltblending used to prepare the samples was also not very effective in breaking up these aggregates.

Although the wax could not be distinguished in the TEM photos of the iPP/wax nanocomposites (Figure 1c), we assumed that most of the wax crystallized separately in the areas between the iPP spherulites, because it has been established previously that the wax co-crystallizes with iPP only at very low wax contents [17]. This separate crystallization of the wax can be expected because iPP crystallizes before the wax. The presence of molten wax during the crystallization must have influenced the crystal growth of the iPP, because the spherulites in Figure 1c are smaller and somewhat differently structured from the spherulites in Figure 1a. Individual Ag nanoparticles and some aggregates (with diameters ranging from 0.11 to $1.53 \mu \mathrm{m}$ ) are observed in Figure 1c. These nanoparticles are only dispersed in between the spherulites (arrow B), with none visible at the growth centres of the spherulites. It looks as if the nanoparticles had a higher affinity for the wax, and therefore remained in the molten wax phase during the crystallization of iPP. They were then trapped in the wax phase after wax crystallization. At higher Ag content the filler particles (with diameters ranging from 0.11 to $1.72 \mu \mathrm{m}$ ) were not well dispersed, and the extent of agglomeration increased (Figure 1d), although it was still lower than in the case of 95/5 w/w iPP/Ag (compare Figures $1 \mathrm{~b}$ and $1 \mathrm{~d}$ ). Nanoparticles are also visible at the growth centres of the iPP spherulites (arrow C).

\subsection{Differential scanning calorimetry (DSC)}

The DSC curves of the iPP/wax blends are not presented, but the samples with $5 \mathrm{wt} \%$ wax showed a single melting peak which is associated with the melting of the iPP crystals. This indicates that the wax and iPP are probably miscible in the molten state, and could have co-crystallized at such a low wax content, although it is quite possible that individual wax chains and very small wax crystals (too small and dispersed to show visible heat flow changes during melting) were trapped in the amorphous part of iPP. However, when the wax content was $10 \mathrm{wt} \%$ and more, two separate melting peaks were visible. 


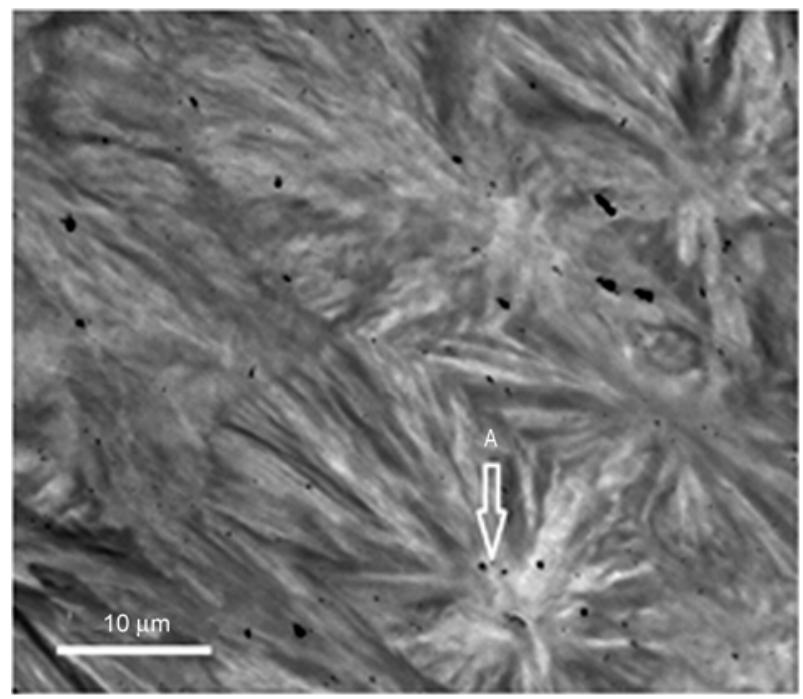

a)

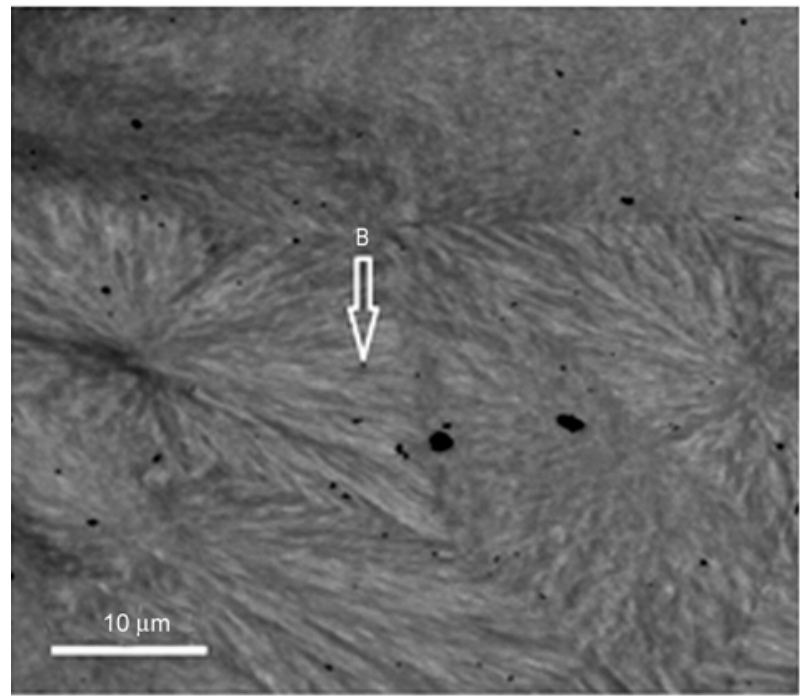

c)

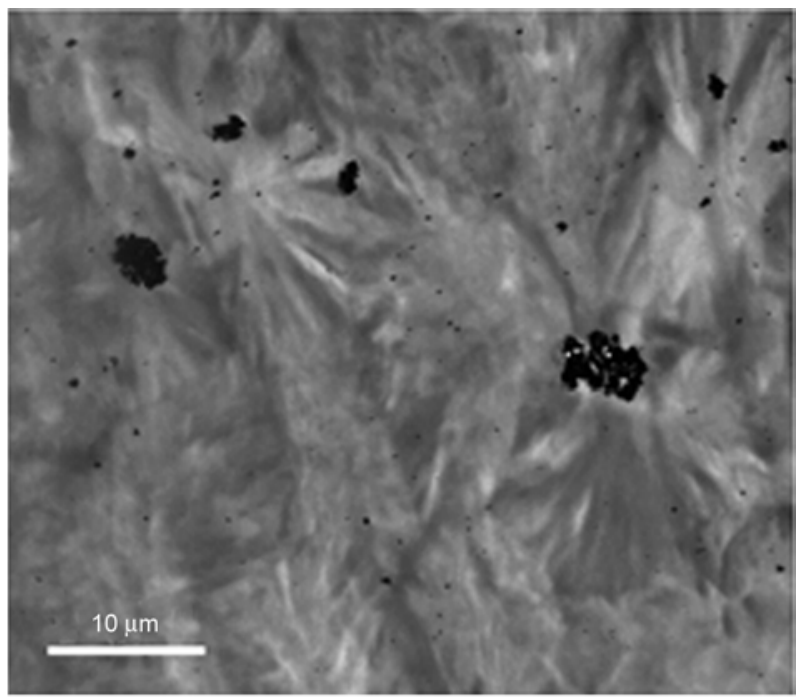

b)

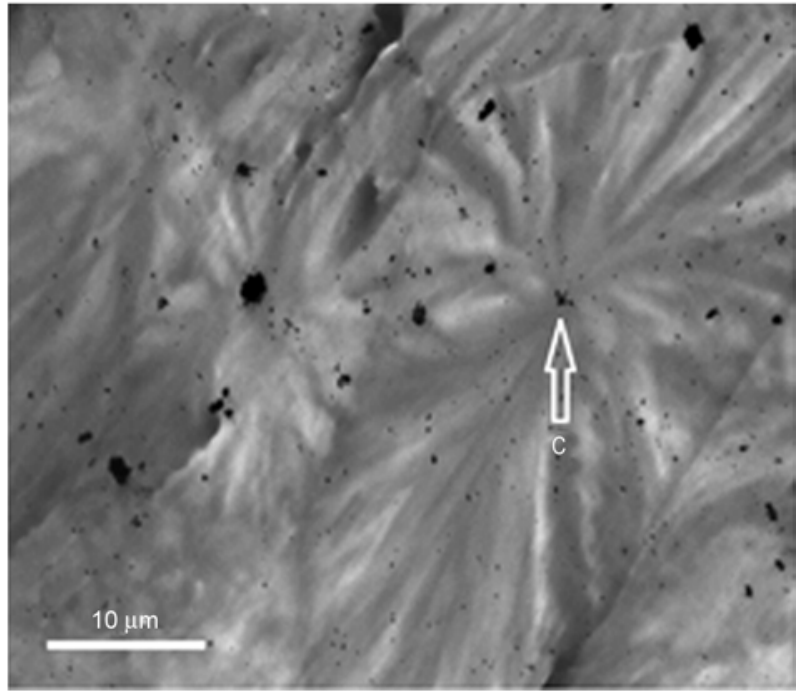

d)

Figure 1. TEM images of (a) 98/2 w/w iPP/Ag, (b) 95/5 w/w iPP/Ag, (c) 88/10/2 w/w iPP/Wax/Ag, and (d) 85/10/5 w/w $\mathrm{iPP} / \mathrm{Wax} / \mathrm{Ag}$ slowly cooled from the melt

These were associated with the melting of wax and iPP crystals, respectively. This was observed in both the slowly cooled and quenched samples. The observed behaviour indicates the (partial) immiscibility of the blend components, and most of the wax crystallized separately from the iPP. Moreover, the melting peaks corresponding to the melting of iPP crystals shifted to lower temperatures with an increase in wax content. Other authors attributed this to the plasticization effect of the paraffin wax $[17,18]$.

At lower wax contents, the normalised melting enthalpies of the wax component are lower than that of pure wax (Table 1). However, at $20 \%$ wax content, they are comparable to that of pure wax. This is probably because the individual wax chains or very small crystals were trapped in the amorphous phase of iPP, or co-crystallized with iPP chains, at low wax content and as a result only a small portion of the wax crystallized separately into sizable crystals. However, at a higher content, more wax crystallized separately from iPP. The normalized melting enthalpies of the iPP component increased with an increase in wax content (Table 1). This confirms the co-crystallization of some of the wax with iPP giving rise to the higher melting enthalpy of iPP. The normalised melting enthalpies of the iPP component in the slowly cooled blends are higher than that in the comparable blends quenched from the melt. This is attributed to the higher crystallinity of the blends slowly cooled from the melt. In the slow cooling process there is enough time for the crystals to form, whereas faster cooling such as quenching reduces the time for crystal nucleation and growth [19]. 
Table 1. DSC melting and crystallization parameters of the investigated samples

\begin{tabular}{|c|c|c|c|c|c|c|c|c|}
\hline \multirow{2}{*}{$\begin{array}{c}\text { Sample } \\
{[\mathbf{w} / \mathbf{w}]}\end{array}$} & \multicolumn{2}{|c|}{$\begin{array}{c}\mathbf{T}_{\mathbf{m}} \\
{\left[{ }^{\circ} \mathbf{C}\right]}\end{array}$} & \multicolumn{2}{|c|}{$\begin{array}{c}\Delta \mathbf{H}_{\mathrm{m}} \\
{\left[\mathbf{J} \cdot \mathrm{g}^{-1}\right]}\end{array}$} & \multicolumn{2}{|c|}{$\begin{array}{c}\Delta \mathbf{H}_{\mathrm{m}}^{\mathbf{n}} \\
{\left[\mathrm{J} \cdot \mathrm{g}^{-1}\right]}\end{array}$} & \multicolumn{2}{|c|}{$\begin{array}{c}\mathbf{T}_{\mathbf{c}} \\
{\left[{ }^{\circ} \mathbf{C}\right]}\end{array}$} \\
\hline & Quenched & Slowly cooled & Quenched & Slowly cooled & Quenched & Slowly cooled & Quenched & Slowly cooled \\
\hline iPP & $163.7 \pm 0.6$ & $163.9 \pm 1.1$ & $79.3 \pm 6.7$ & $100.0 \pm 5.1$ & - & - & $104.6 \pm 0.8$ & $102.1 \pm 1.2$ \\
\hline Wax & $60.7 \pm 0.4$ & $60.7 \pm 0.4$ & $137.5 \pm 7.6$ & $137.5 \pm 7.6$ & - & - & $43.2 \pm 0.8$ & $43.2 \pm 0.8$ \\
\hline \multicolumn{9}{|c|}{ iPP/wax } \\
\hline 95/5 iPP/wax & $161.0^{\mathrm{b}} \pm 0.6$ & $160.8^{\mathrm{b}} \pm 0.2$ & $81.3^{\mathrm{b}} \pm 3.5$ & $96.9^{\mathrm{b}} \pm 2.2$ & $85.6^{\mathrm{b}}$ & $102.0^{\mathrm{b}}$ & $107.2^{\mathrm{b}} \pm 0.3$ & $99.7^{b} \pm 0.6$ \\
\hline $90 / 10$ & $59.3^{\mathrm{a}} \pm 0.8$ & $55.0^{\mathrm{a}} \pm 0.3$ & $5.9^{\mathrm{a}} \pm 3.6$ & $6.9^{\mathrm{a}} \pm 0.7$ & $59.0^{\mathrm{a}}$ & 69.0 & $43.7^{\mathrm{a}} \pm 0.3$ & $42.2^{\mathrm{a}} \pm 0.3$ \\
\hline $\mathrm{iPP} / \mathrm{wax}$ & $161.1^{\mathrm{b}} \pm 0.4$ & $161.0^{\mathrm{b}} \pm 1.0$ & $83.5^{\mathrm{b}} \pm 3.7$ & $86.0^{\mathrm{b}} \pm 3.0$ & $92.8^{\mathrm{b}}$ & 95.6 & $103.2^{\mathrm{b}} \pm 0.3$ & $102.2^{\mathrm{b}} \pm 4.9$ \\
\hline $80 / 20$ & $56.6^{\mathrm{a}} \pm 3.2$ & $59.7^{\mathrm{a}} \pm 3.2$ & $12.0^{\mathrm{a}} \pm 1.8$ & $17.6^{\mathrm{a}} \pm 6.1$ & $120.0^{\mathrm{a}}$ & $176.0^{\mathrm{a}}$ & $41.6^{\mathrm{a}} \pm 0.3$ & $40.9^{a} \pm 0.5$ \\
\hline iPP/wax & $158.2^{\mathrm{b}} \pm 0.8$ & $157.3^{\mathrm{b}} \pm 1.9$ & $82.2^{\mathrm{b}} \pm 3.2$ & $100.2^{\mathrm{b}} \pm 5.3$ & $102.8^{\mathrm{b}}$ & $125.3^{\mathrm{b}}$ & $99.4^{\mathrm{b}} \pm 3.5$ & $97.2^{\mathrm{b}} \pm 0.8$ \\
\hline \multicolumn{9}{|c|}{ iPP/wax/Ag } \\
\hline $88 / 10 / 2$ & $51.0^{\mathrm{a}} \pm 0.4$ & $55.3^{\mathrm{a}} \pm 0.3$ & $1.7^{\mathrm{a}} \pm 0.2$ & $6.0^{\mathrm{a}} \pm 0.2$ & $17.0^{\mathrm{a}}$ & $60.0^{\mathrm{a}}$ & $45.2^{\mathrm{a}} \pm 0.6$ & $42.6^{\mathrm{a}} \pm 0.3$ \\
\hline $\mathrm{iPP} / \mathrm{wax} / \mathrm{Ag}$ & $160.2^{\mathrm{b}} \pm 0.2$ & $166.2^{\mathrm{b}} \pm 1.4$ & $74.1^{\mathrm{b}} \pm 3.1$ & $92.8^{\mathrm{b}} \pm 1.7$ & $84.2^{\mathrm{b}}$ & $105.5^{\mathrm{b}}$ & $105.6^{\mathrm{b}} \pm 0.3$ & $100.1^{\mathrm{b}_{ \pm}} .3$ \\
\hline $87 / 10 / 3$ & $51.6^{\mathrm{a}} \pm 0.2$ & $53.7^{\mathrm{a}} \pm 0.9$ & $4.3^{\mathrm{a}} \pm 0.3$ & $4.4^{\mathrm{a}} \pm 0.9$ & $43.0^{\mathrm{a}}$ & $44.0^{\mathrm{a}}$ & $43.1^{\mathrm{a}} \pm 0.3$ & $43.4^{\mathrm{a}} \pm 0.5$ \\
\hline $\mathrm{iPP} / \mathrm{wax} / \mathrm{Ag}$ & $161.9^{\mathrm{b}} \pm 0.2$ & $162.1^{\mathrm{b}} \pm 0.7$ & $71.7^{\mathrm{b}} \pm 1.0$ & $83.8^{\mathrm{b}} \pm 4.3$ & $82.4^{\mathrm{b}}$ & $96.3^{\mathrm{b}}$ & $98.9^{b} \pm 0.5$ & $100.4^{\mathrm{b}} \pm 1.1$ \\
\hline $86 / 10 / 4$ & $54.9^{\mathrm{a}} \pm 2.8$ & $54.0^{\mathrm{a}} \pm 1.2$ & $3.4^{\mathrm{a}} \pm 1.3$ & $5.4^{\mathrm{a}} \pm 2.0$ & $34.0^{\mathrm{a}}$ & $54.0^{\mathrm{a}}$ & $43.1^{\mathrm{a}} \pm 0.3$ & $42.2^{\mathrm{a}} \pm 0.3$ \\
\hline $\mathrm{iPP} / \mathrm{wax} / \mathrm{Ag}$ & $162.5^{\mathrm{b}} \pm 0.9$ & $162.1^{\mathrm{b}} \pm 0.7$ & $72.5^{\mathrm{b}} \pm 8.0$ & $82.5^{\mathrm{b}} \pm 3.4$ & $84.3^{\mathrm{b}}$ & $95.9^{\mathrm{b}}$ & $100.9^{b} \pm 0.9$ & $100.1^{\mathrm{b}_{ \pm}} 0.3$ \\
\hline $85 / 10 / 5$ & $54.8^{\mathrm{a}} \pm 1.6$ & $53.1^{\mathrm{a}} \pm 0.7$ & $3.8^{\mathrm{a}} \pm 0.5$ & $4.4^{\mathrm{a}} \pm 1.0$ & $38.0^{\mathrm{a}}$ & $44.0^{\mathrm{a}}$ & $44.1^{\mathrm{a}} \pm 0.3$ & $44.2^{\mathrm{a}} \pm 0.3$ \\
\hline $\mathrm{iPP} / \mathrm{wax} / \mathrm{Ag}$ & $162.0^{\mathrm{b}} \pm 0.1$ & $160.5^{\mathrm{b}} \pm 0.7$ & $69.4^{\mathrm{b}} \pm 1.3$ & $83.4^{\mathrm{b}} \pm 3.9$ & $81.6^{\mathrm{b}}$ & $98.1^{\mathrm{b}}$ & $101.9^{\mathrm{b}} \pm 0.5$ & $101.9^{\mathrm{b}} \pm 0.5$ \\
\hline \multicolumn{9}{|c|}{ iPP/Ag } \\
\hline 98/2 iPP/Ag & $165.0 \pm 0.5$ & $165.3 \pm 0.7$ & $79.6 \pm 1.6$ & $97.2 \pm 2.9$ & 81.2 & 99.2 & $106.7 \pm 0.8$ & $104.2 \pm 0.3$ \\
\hline 97/3 iPP/Ag & $165.3 \pm 0.4$ & $165.3 \pm 0.7$ & $73.7 \pm 5.8$ & $95.0 \pm 3.0$ & 76.0 & 97.9 & $107.7 \pm 0.3$ & $106.7 \pm 0.6$ \\
\hline 96/4 iPP/Ag & $167.3 \pm 1.9$ & $165.8 \pm 1.2$ & $75.1 \pm 2.0$ & $95.0 \pm 3.2$ & 78.2 & 99.0 & $107.9 \pm 0.9$ & $108.1 \pm 0.3$ \\
\hline 95/5 iPP/Ag & $165.6 \pm 0.7$ & $167.1 \pm 1.4$ & $73.3 \pm 2.6$ & $89.9 \pm 2.7$ & 77.2 & 94.6 & $107.4 \pm 0.5$ & $106.6 \pm 0.3$ \\
\hline
\end{tabular}

$T_{\mathrm{m}}$ - melting peak temperature, $T_{\mathrm{c}}-$ crystallization peak temperature, $\Delta H_{\mathrm{m}}^{\mathrm{n}}-$ melting enthalpy normalised with respect to the wax and PP contents in the respective samples

${ }^{a}$ Melting/crystallization of wax

${ }^{b}$ Melting/crystallization of PP

Both the slowly cooled and quenched $\mathrm{iPP} / \mathrm{wax} / \mathrm{Ag}$ nanocomposites containing $10 \mathrm{wt} \%$ wax showed two separate melting peaks associated with the melting of wax and iPP crystals. There are no significant changes in the melting temperatures and normalised enthalpies of the iPP component with an increase in $\mathrm{Ag}$ content for both the quenched and slowly cooled samples (Table 1). This indicates that the presence of Ag nanoparticles had little influence on the crystallite sizes and mobility of the polymer chains. However, if the normalized enthalpies of the quenched and slowly cooled samples are compared, it is clear that the melting enthalpies of the slowly cooled samples are higher than those of the quenched samples. This is the result of the higher crystallinity of the slowly cooled samples. The crystallization and melting temperatures of the quenched and slowly cooled iPP/wax blends and iPP/wax/Ag blend composites are very similar within experimental error, although the values are slightly lower at higher wax content for the iPP/wax blends (Table 1). Wax normally acts as a plasticizer by enhancing the mobility of the polymer chains, leading to lower crystallization and melting temperatures. However, when Ag nanoparticles are present, they can act as nucleating sites for the crystallization of iPP, and this will give rise to higher crystallization and melting temperatures. It therefore seems as if the opposing effects of wax and $\mathrm{Ag}$ on iPP crystallization balance each other in the iPP/ wax/Ag blend composites, which causes the crystallization and melting temperatures of iPP to remain unchanged.

Both the quenched and slowly cooled iPP/Ag nanocomposites showed a single melting peak associated with the melting of the PP crystals. There are no significant differences between the enthalpies of $\mathrm{iPP}$ in the iPP/Ag nanocomposites and that of pure iPP for both the quenched and slowly cooled samples (Table 1). However, the melting and crystallization temperatures are slightly higher than that of pure iPP. It is clear from this observation that the presence of Ag nanoparticles reduces the iPP chain mobility, as already mentioned before. The melting enthalpies of the slowly cooled composites are higher than those of the comparable composites quenched from the melt. The reason for this has already been discussed. 


\subsection{Dynamic mechanical analysis (DMA)}

The storage modulus curve of iPP in Figure $2 \mathrm{a}$ shows a minimum at about $70^{\circ} \mathrm{C}$, which is not visible in Figure 2b. This is the result of the re-crystallization of the quenched sample during the relatively slow heating in the DMA instrument. The minima observed for the other samples are related to re-crystallization effects or to the melting of the wax in the blends and composites. The storage modulus of the quenched iPP shown in Figure 2a increases with the addition of $10 \mathrm{wt} \%$ wax. This is attributed to the increase in crystallinity because of the much higher crystallinity of the wax. However, the storage modulus of the $\mathrm{iPP} / \mathrm{Ag}$ nanocomposite changed very little compared to that of pure iPP, which indicates that the nanoparticle content was too small and the interaction with the polymer was too weak to significantly influence the polymer stiffness. When both wax and Ag are present, the storage modulus of the nanocomposites is very similar to that of the iPP/wax sample. This confirms that the highly crystalline wax provided more stiffness to the sample, while the small amount of Ag had very little influence.

In the slowly cooled samples, the storage modulus of the iPP/wax samples is significantly lower than that of iPP (Figure 2b). This can be attributed to a decrease in iPP crystallinity, or to a softening effect of the much softer wax. If one looks at the values in Table 1, it is clear that the normalised melting enthalpy of iPP in the 90/10 w/w iPP/wax sample is slightly lower than that of pure iPP, although very similar within experimental error. It is therefore doubtful that the decrease in storage modulus is the result of lower iPP crystallinity.

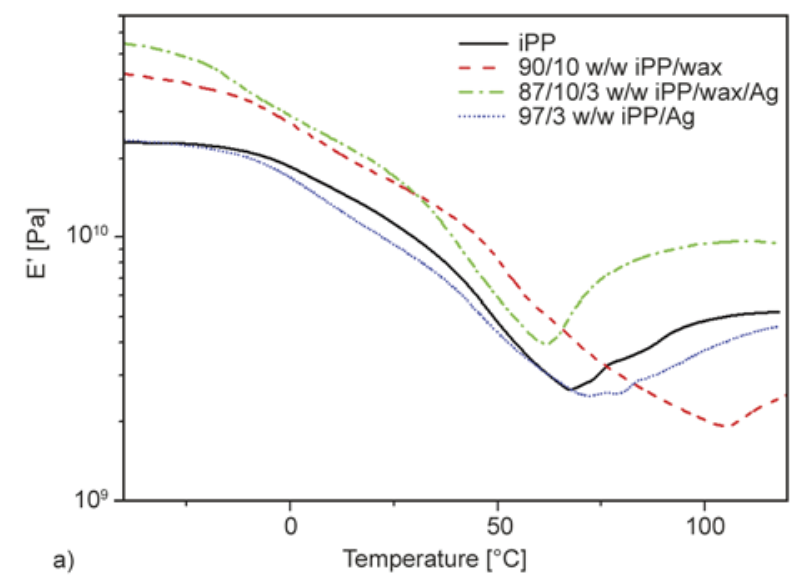

When comparing the storage modulus of the iPP/Ag sample with that of iPP and iPP/wax, it can be seen that it is lower than that of iPP, but higher than that of iPP/wax. According to Table 1 the melting enthalpies of $\mathrm{iPP}$ and $\mathrm{iPP}$ in $\mathrm{iPP} /$ wax and $\mathrm{PP} / \mathrm{Ag}$ are very similar, so the differences in their storage moduli cannot be the result of differences in iPP crystallinity. It has been reported previously that the nanoparticles can have a plasticizing effect on a polymer [20], and therefore the lower storage modulus in the case of $\mathrm{iPP} / \mathrm{Ag}$ is probably the result of such a plasticizing effect. The storage modulus is the lowest when both wax and Ag are present. Again the melting enthalpy of iPP in iPP/wax/Ag is not much different from that of pure iPP (Table 1), and therefore the reduction in storage modulus cannot be the result of a change in crystallinity. It is expected that there will be a very weak interaction between iPP and wax, while it seems as if there is a strong interaction between wax and Ag (section 3.1). The wax-covered Ag particles will then increase the free volume in the sample, which will give rise to higher iPP chain mobility in the amorphous phase and reduced stiffness.

The $\tan \delta$ curves in Figure 3a show that the quenched iPP has two relaxation peaks associated with the $\beta$ and $\alpha$-relaxations, respectively at about 10 and $70^{\circ} \mathrm{C}$. The $\beta$-relaxation is usually associated with motions within the amorphous regions during the glass transition, and the $\alpha$-relaxation is related to the crystalline phase of the polymer [19]. When wax was present, an additional peak appeared at about $60^{\circ} \mathrm{C}$, which is associated with the wax melting. The $\beta$ peak of the iPP/wax sample looks very similar to that of pure iPP, and appears at about the same tem-

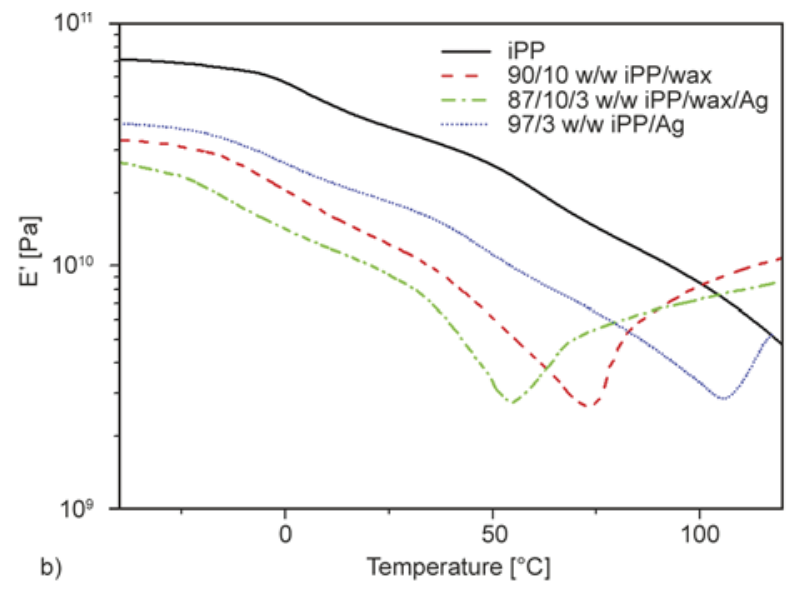

Figure 2. Storage modulus as a function of temperature of iPP, iPP/wax, iPP/Ag and iPP/wax/Ag samples (a) quenched and (b) slowly cooled from the melt 

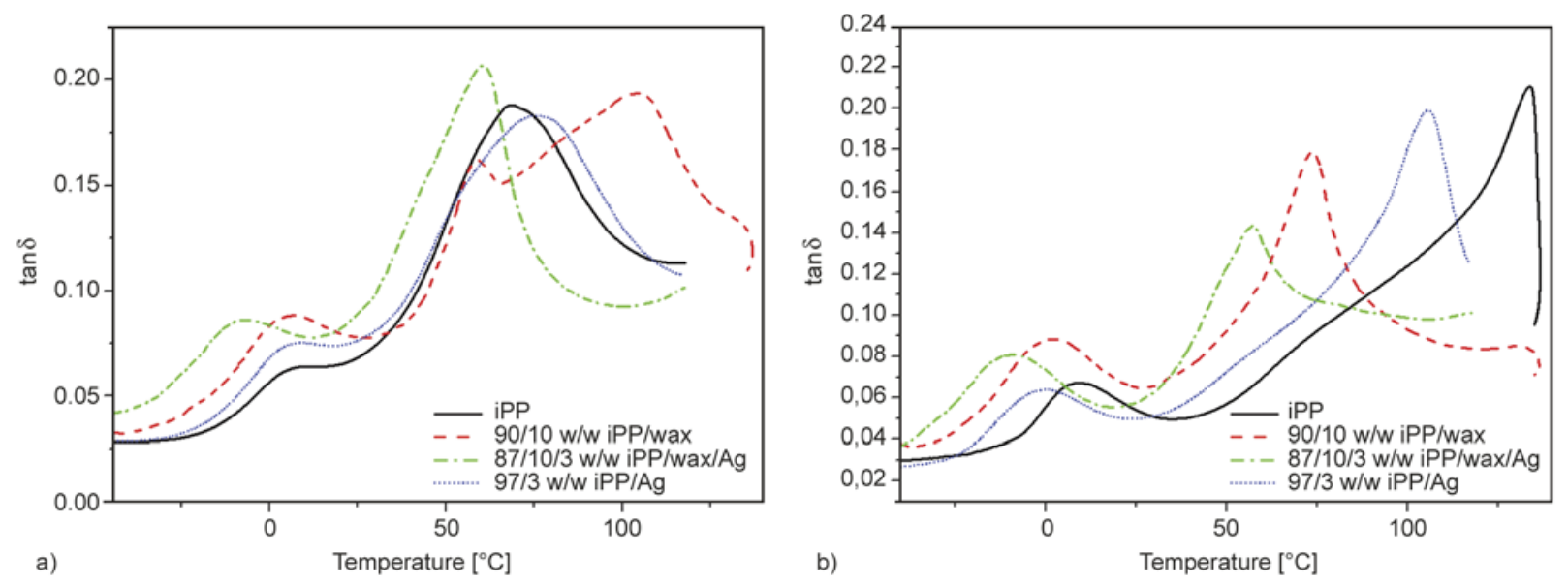

Figure 3. Loss factor as a function of temperature of iPP, iPP/wax, iPP/Ag and iPP/wax/Ag nanocomposites (a) quenched and (b) slowly cooled from the melt

perature, while the $\alpha$-peak moved to higher temperatures. This indicates that the highly crystalline wax did not influence the iPP chain mobility in the amorphous phase, but in some way influenced the crystalline phase of iPP. According to Table 1 the normalised melting enthalpy of iPP in the blend is higher than that of the pure iPP, which could explain the increase in the $\alpha$-transition temperature if one assumes some co-crystallization of the wax with iPP. The iPP/Ag sample also shows two relaxation peaks associated with the $\beta$ - and $\alpha$-relaxations. The temperature of the $\beta$-peak is very similar to that of iPP, but the $\alpha$-peak appeared at a slightly higher temperature. This can be attributed to the dispersion of the Ag particles in the inter-crystalline amorphous areas of the iPP, and therefore they will have an immobilizing effect on these chain segments. However, in the presence of both Ag and wax, only the $\beta$-relaxation and the wax melting peaks are visible. The $\alpha$-peak is not visible in the investigated temperature range. The $\beta$-peak appeared at an observably lower temperature and the wax melting is much more prominent than that of the iPP/wax blend. It is expected that there will be a weak interaction between iPP and wax, while there is a stronger interaction between wax and Ag. The wax-covered Ag particles will then increase the free volume in the sample, which will give rise to higher iPP chain mobility in the amorphous phase, leading to lower $T_{\mathrm{g}}$ values. It is not clear why the $\alpha$-peak has disappeared, unless it has moved to an even higher temperature outside our analysis range.

The slowly cooled iPP has two relaxation peaks associated with the $\beta$ - and $\alpha$-relaxations at about 10 and $130^{\circ} \mathrm{C}$ (Figure 3b). When wax is present there are also two relaxation peaks, respectively associated with the glass transition and wax melting. The $\alpha$-peak is not visible in the investigated temperature range, probably because wax has crystallized in the inter-crystalline amorphous regions of $\mathrm{iPP}$, and as a result reduced the mobility of these chain segments. The $\beta$-peak of the iPP/wax sample is at a lower temperature than that of the pure iPP, which can be attributed to the increase in free volume because of the relatively weak interaction between iPP and wax, which gives rise to higher iPP chain mobility in the amorphous phase. The iPP/Ag nanocomposites also have two relaxation peaks associated with the $\beta$ - and $\alpha$-transitions. In this case both the $\beta$ - and $\alpha$-peaks appear at lower temperatures than those of pure iPP. This is an indication that Ag particles to some extent have plasticized iPP, giving rise to an increase in iPP chain mobility in the amorphous phase [20]. The decrease in the $\alpha$-transition temperature must be related to the presence of the Ag particles in the inter-crystalline amorphous areas of iPP. It is, however, not clear exactly how these particles influenced the relaxation of the chains in these areas, since for the quenched samples the temperature of this transition increased. When both wax and $\mathrm{Ag}$ were present, the observation is similar to that of the quenched sample, and the explanation will be the same.

Figure 4 compares the storage modulus curves of the quenched and slowly cooled samples. The storage modulus of the slowly cooled iPP and iPP/Ag nanocomposites is much higher than that of the quenched samples (Figures $4 \mathrm{a}$ and $4 \mathrm{~b}$ ). This is attributed to the higher crystallinity of the slowly cooled samples, as can be seen from the higher normalised 

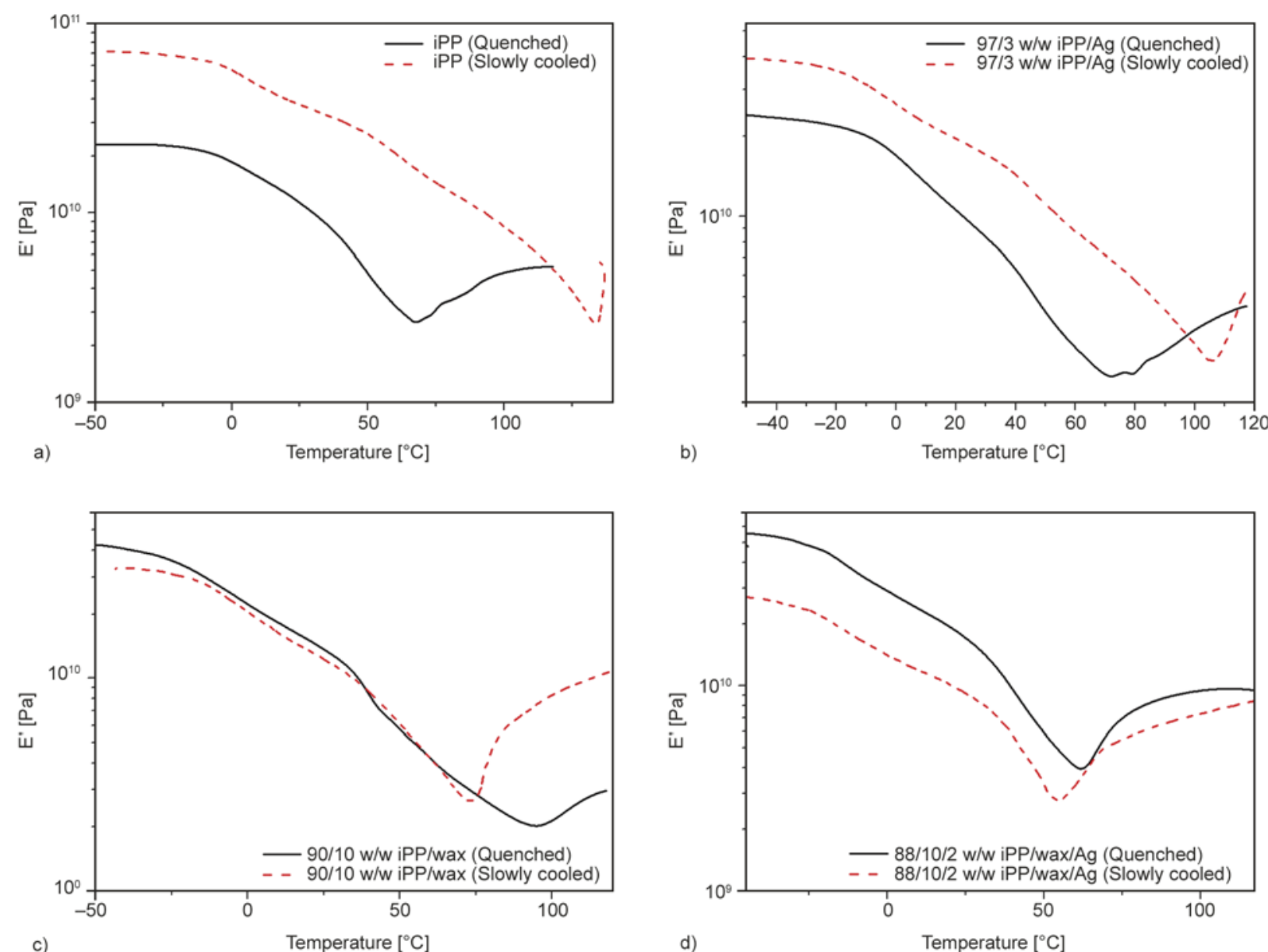

Figure 4. Storage modulus as a function of temperature of the quenched and slowly cooled (a) iPP, (b) iPP/wax, (c) iPP/Ag and (d) $\mathrm{iPP} /$ wax/Ag nanocomposites

melting enthalpies of the slowly cooled samples (Table 1). However, the quenched and slowly cooled iPP/wax samples show almost the same modulus (Figure 4c), indicating that the presence of the soft wax counter-acted the influence of the higher crystallinity of the slowly cooled blend. When both wax and $\mathrm{Ag}$ are present, the storage modulus of the slowly cooled sample is significantly lower than that of the quenched sample (Figure 4d). According to Table 1 the normalised melting enthalpy of iPP in the slowly cooled $\mathrm{PP} / \mathrm{wax} / \mathrm{Ag}$ is higher than that in the quenched sample, and the differences in storage modulus is therefore not related to the differences in crystallinity. The only possible reason for this observation is that more wax crystallized around the nanoparticles in the quenched samples, giving rise to more rigidity from the wax-covered $\mathrm{Ag}$ filler.

There is no difference between the temperatures of the $\beta$-peaks in the quenched and slowly cooled iPP (Figure 5a), which is to be expected because differences in cooling rate will only influence the crystallinity of iPP. The $\alpha$-peak of the slowly cooled iPP appears at a significantly higher temperature than that of the quenched iPP. This is attributed to the higher crystallinity of the slowly cooled samples (compare melting enthalpy values in Table 1). If one compares the relaxation peaks of the iPP/Ag samples, it can be seen that the $\beta$-peak of the slowly cooled iPP/Ag sample appears at a lower temperature, but the $\alpha$-peak is still at a higher temperature, than those of the quenched samples (Figure 5b). The difference between the $\alpha$-peaks of the samples is attributed to the difference in crystallinity between the quenched and slowly cooled samples (Table 1), although Ag had an influence in both cases, as discussed before. Therefore, the presence of Ag particles in the inter-crystalline amorphous regions (section 3.1) influences the crystalline phase more than the amorphous phase in the slowly cooled sample, because of its higher crystallinity, but the amorphous phase more than the crystalline in the quenched sample, which has a lower crystallinity.

In the $\mathrm{iPP} /$ wax samples, the $\beta$-relaxation and wax melting peaks of the slowly cooled sample appear at 

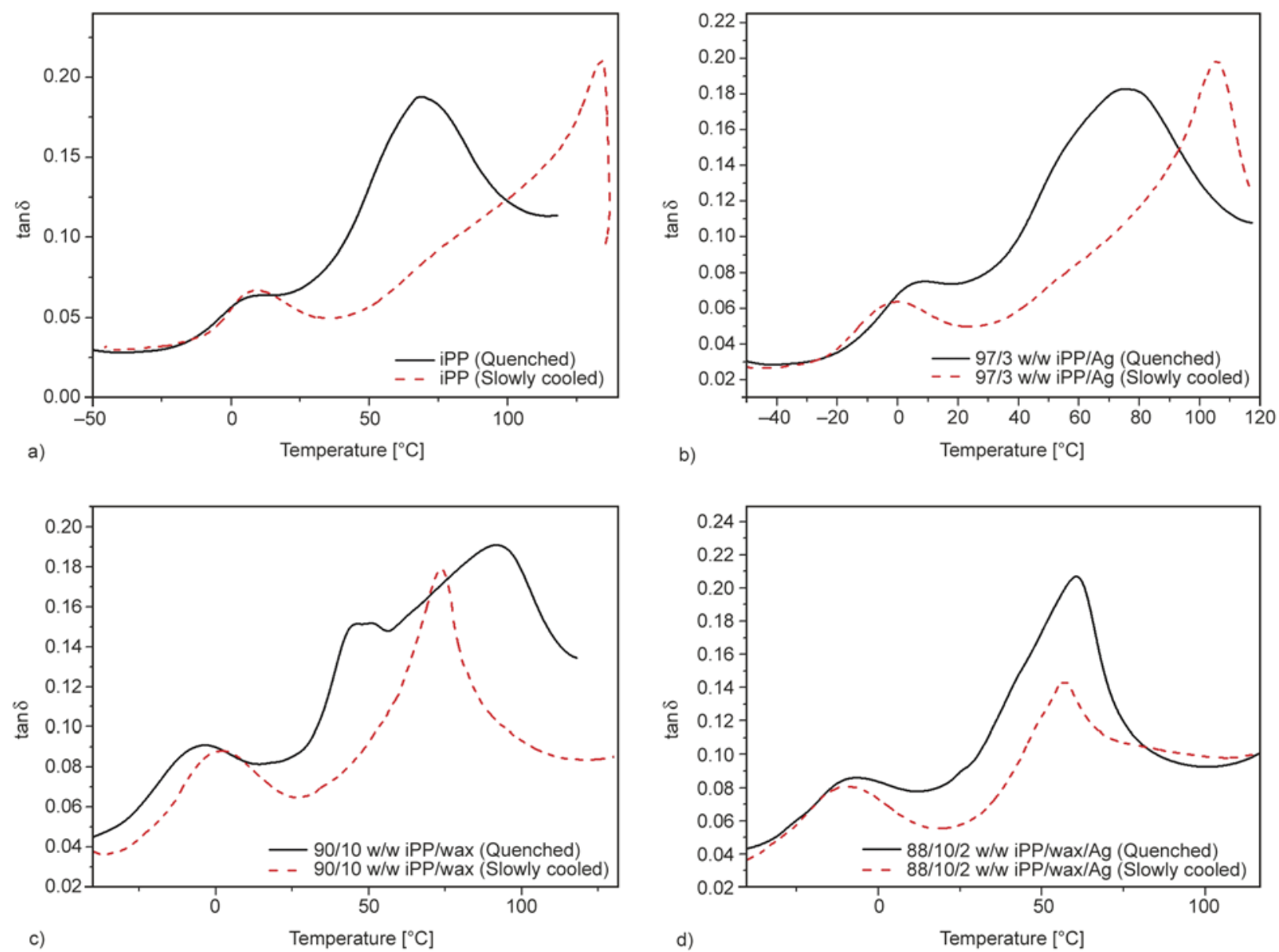

Figure 5. Loss factor as a function of temperature of the quenched and slowly cooled (a) iPP, (b) iPP/Ag, (c) iPP/wax and (d) $\mathrm{iPP} / \mathrm{wax} / \mathrm{Ag}$ nanocomposites

a higher temperature than those of the quenched sample (Figure 5c). This is because larger wax crystals formed during slow cooling, which had a stronger immobilizing effect on the amorphous iPP chains and which had melted at higher temperatures. There is little difference between the $\beta$-transition and wax melting temperatures of the quenched and slowly cooled samples when both wax and Ag were present (Figure 5d), because the wax crystallized mostly around the Ag nanoparticles, and since the rate at which the sample was cooled would not seriously affect the wax crystallization, and since there is very little interaction between iPP and wax, it could be expected that these transitions would not be seriously affected by the rate at which the samples were cooled.

\subsection{Thermal conductivity}

The thermal conductivities of the quenched and slowly cooled iPP samples increased with increasing Ag content at lower Ag contents, but leveled off at higher contents (Figure 6). This can be attributed to a better dispersion of the $\mathrm{Ag}$ particles at lower contents. At higher Ag contents the particles were not so well dispersed and formed agglomerates (Figure 1b). It has been reported previously that the agglomeration of filler particles increased with an increase in filler content [21], and that these agglomerations gave rise to lower thermal conductivities [22]. In the $\mathrm{iPP} / \mathrm{Ag}$ nanocomposites, phonons are transported from one Ag particle to another via the polymer. Since the polymer is not a good thermal conductor, it is important that the filler particles must be well dispersed and fairly close to each other, and that there should be fairly strong interactive forces between iPP and Ag. In such a case heat will be transported by high frequency phonon vibrations leading to higher thermal conductivity values. However, if the particles are poorly dispersed and/or the interaction between iPP and Ag is weak, a small amount of heat will be transported by low frequency phonons as a result of higher thermal contact resistance. When the thermal conductivities of the quenched and slowly cooled samples are compared (Figure 6), it can be 


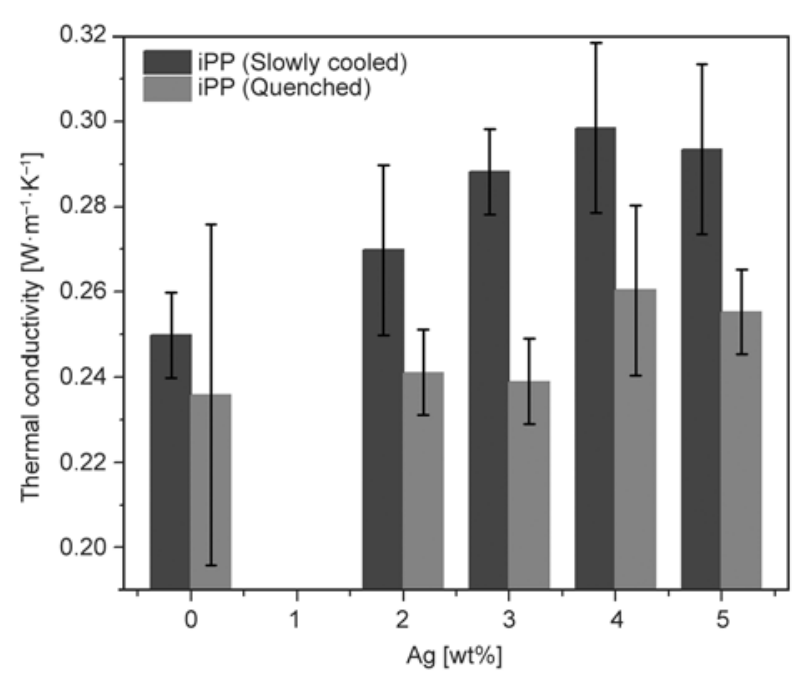

Figure 6. Thermal conductivities of $\mathrm{iPP}$ and $\mathrm{iPP} / \mathrm{Ag}$

seen that the thermal conductivities of the quenched samples are significantly lower than those of the slowly cooled samples. It is known that higher crystallinities give rise to better thermal energy transport [23], which is also the reason for the better thermal conductivity of the slowly cooled samples, that have previously been shown to have much higher crystallinities.

The thermal conductivity of the quenched iPP shown in Figure 7 slightly increases after the addition of $10 \mathrm{wt} \%$ wax. This can be attributed to the wax crystals in the sample, which increased the total crystallinity and therefore the thermal energy transport. The thermal conductivity of $\mathrm{iPP} / \mathrm{Ag}$ is slightly lower than that of $\mathrm{iPP} /$ wax, but is very similar to that of pure iPP. Again, if one looks at the values in Table 1, it is clear that the normalised melting enthalpy of the $\mathrm{iPP} / \mathrm{Ag}$ sample is very similar within experi-

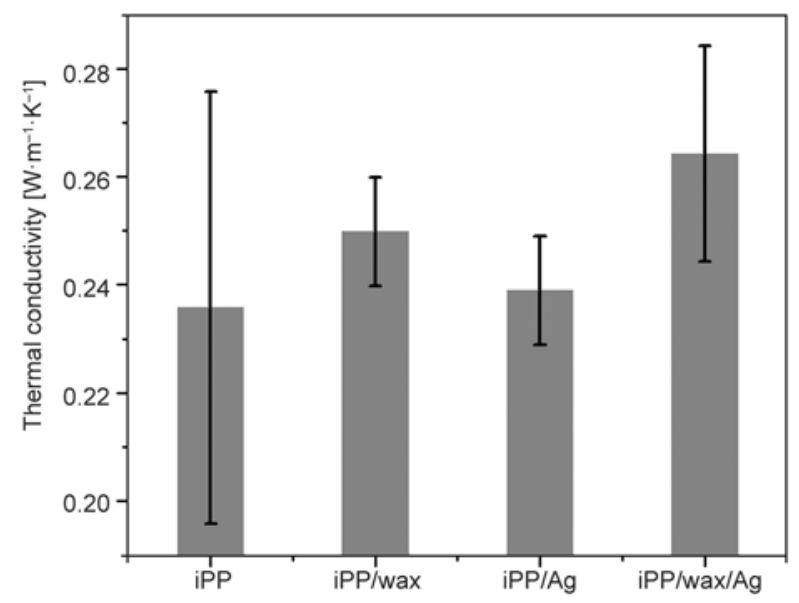

Figure 7. Thermal conductivities of quenched iPP, 90/10 w/w $\mathrm{iPP} / \mathrm{wax}, 97 / 3 \mathrm{w} / \mathrm{w} \mathrm{iPP} / \mathrm{Ag}$ and $87 / 10 / 3 \mathrm{w} / \mathrm{w}$ $\mathrm{iPP} / \mathrm{wax} / \mathrm{Ag}$ mental error to that of pure iPP, but lower than that of iPP/wax. As already seen, the crystallinities of the quenched samples are significantly lower, and therefore the Ag particles are probably dispersed in the amorphous phase of iPP with little contact with the crystallites, which could inhibit the thermal transport through the $\mathrm{iPP} / \mathrm{Ag}$ samples. Although $\mathrm{Ag}$ is thermally more conductive than wax and iPP, it is clear that the thermal conductivity of the quenched iPP sample depends more on the crystallinity than on the presence of conductive metal particles. When both wax and Ag are present, the thermal conductivity of the sample is higher than that of $\mathrm{PP} / \mathrm{Ag}$. This can again be attributed to the higher crystallinity of the sample, but also to the dispersion of $\mathrm{Ag}$ within the highly crystalline wax phase. The wax-covered $\mathrm{Ag}$ particles therefore significantly increased the thermal conductivity of the quenched iPP sample. In the slowly cooled samples (Figure 8), the thermal conductivity of $\mathrm{iPP} /$ wax is observably higher than that of iPP, which is also the result of the presence of the more crystalline wax. The thermal conductivity of the $\mathrm{iPP} / \mathrm{Ag}$ sample is significantly higher than those of the pure iPP and the iPP/wax samples. According to Table 1, the slowly cooled iPP/Ag sample has a much higher crystallinity than the quenched sample, and therefore the Ag particles should have better contact with the iPP crystallites, which probably is the reason for the improved thermal energy transport in the slowly cooled iPP/Ag sample. The thermal conductivity of the $\mathrm{iPP} / \mathrm{wax} / \mathrm{Ag}$ sample is about the same as that of the $\mathrm{PP} / \mathrm{Ag}$ sample. In the slowly cooled iPP/Ag sample, Ag particles act as nucleation centers and are therefore in intimate con-

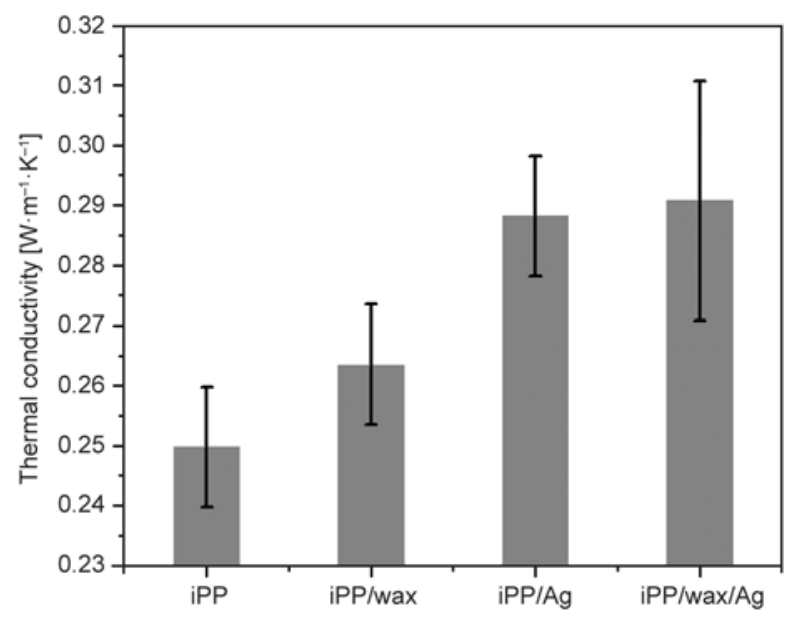

Figure 8. Thermal conductivities of slowly cooled iPP, 90/10 w/w iPP/wax, 97/3 w/w $\mathrm{iPP} / \mathrm{Ag}$ and $87 / 10 / 3 \mathrm{w} / \mathrm{w} \mathrm{iPP} / \mathrm{wax} / \mathrm{Ag}$ 
tact with the iPP crystallites. However, when wax is present, the Ag particles are no longer in contact with the iPP crystallites, but are probably covered by the crystalline wax, which will also improve the thermal energy transport. Crystallites in contact with the Ag nanoparticles, whether they are iPP or wax crystallites, seem to have a very strong influence on the thermal conductivities of the nanocomposites.

There is no specific trend in the thermal conductivities of the quenched and slowly cooled iPP/wax/Ag samples shown in Figure 9. In this case there is a complex combination of effects that will influence the thermal conductivities of the samples: (1) Ag dispersion; (2) extent of agglomeration; (3) covering of Ag particles by crystalline wax; (4) extent of formation and dispersion of wax crystals in between the iPP spherulites. If the filler particles are not well dispersed, and if there are fewer (iPP or wax) crystal-

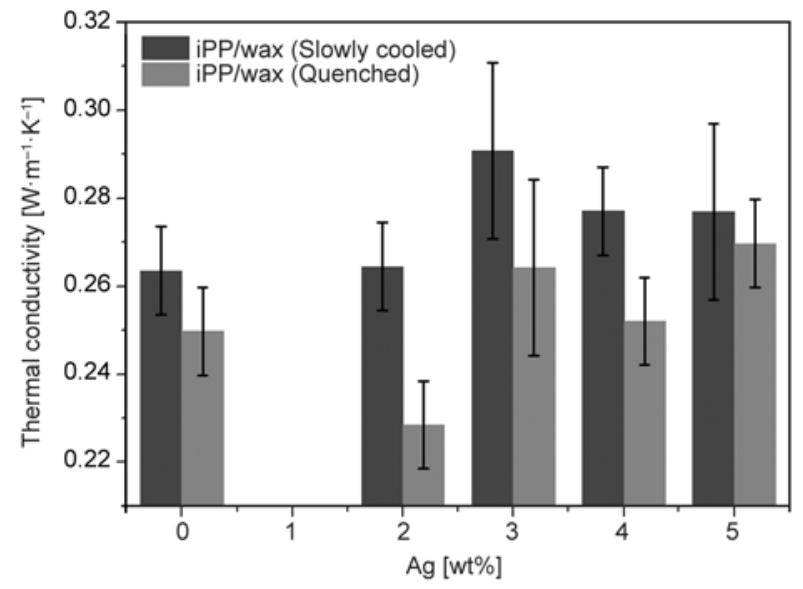

Figure 9. Thermal conductivity of $\mathrm{iPP} /$ wax and $\mathrm{iPP} / \mathrm{Ag}$ with 10 wt $\%$ wax

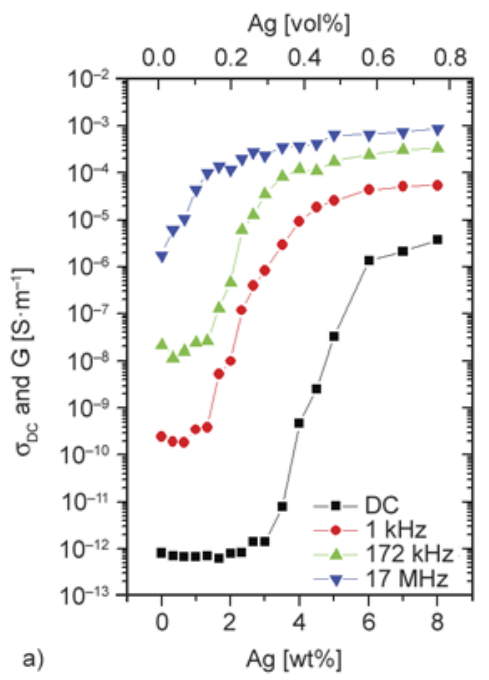

lites, high frequency phonon movement will be inhibited and the thermal conductivity will be lower. The separate crystallization of the wax in the areas between the iPP spherulites and the covering of the Ag particles by the crystalline wax should improve the thermal conductivity, but the weak interaction between iPP and wax may negatively influence the thermal conductivity. All these factors will contribute in one way or the other to the thermal conductivity, but it is difficult to isolate any one of these factors as possible reason(s) for the differences in the conductivity. However, when the thermal conductivities of the slowly cooled and quenched samples are compared, it is clear that the slowly cooled samples have higher thermal conductivities than the quenched samples because of their higher crystallinities.

\subsection{Dielectric properties}

Figure 10 presents the DC conductivity, conductance and susceptance of the $10 \mathrm{wt} \%$ wax containing $\mathrm{PP} / \mathrm{Ag}$ nanocomposites. The DC conductivity of the $\mathrm{iPP} / \mathrm{wax} / \mathrm{Ag}$ samples showed little change up to $3 \mathrm{wt} \% \mathrm{Ag}$, but increased significantly at higher Ag contents. For the lower filler content, the mean distance between the individual metal particles and aggregates must have been too large and the conductivity was therefore controlled by the insulating polymer matrix. When the distances between individual filler particles are large, electrons do not easily hop from one particle to the other. However, at higher Ag contents the individual particles and aggregates were closer to each other and the mean dis-

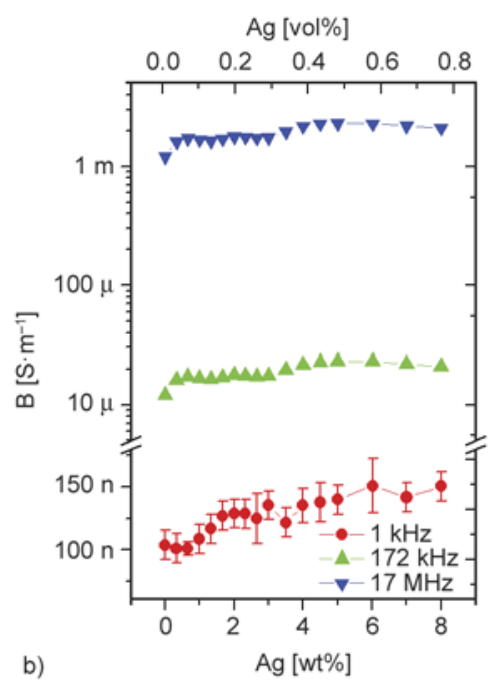

Figure 10. (a) $D C$ conductivity and conductance, and (b) susceptance of $10 \mathrm{wt} \%$ wax containing iPP/Ag composites as function of Ag content 
tance between the metal particles was small enough for the electrons to fairly easily hop from one particle to another. The conductance at different frequencies showed similar behaviour (Figure 10a), but the susceptance only showed small changes with increasing Ag content (Figure 10b). This is probably because the Ag particles do not improve the polarity of the blend. Both the conductance and susceptance increased with increasing frequency for all the investigated $\mathrm{Ag}$ concentrations, which indicates that the Ag particles did not form a well-developed conductive network. However, if one looks at the $D C$ conductivity of the $10 \mathrm{wt} \%$ wax containing $\mathrm{iPP} / \mathrm{Ag}$ samples, a significant increase in the $D C$ conductivity is observed in the samples with $4 \mathrm{wt} \% \mathrm{Ag}$. This increase in the $D C$ conductivity was not observed in

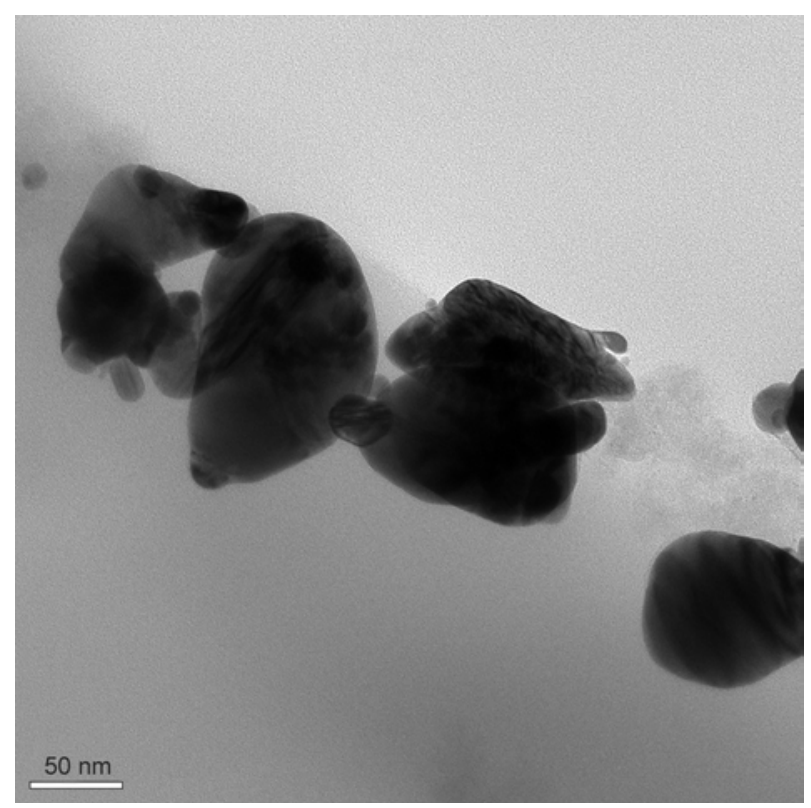

Figure 11. High-magnification TEM photo of Ag nanoparticles $89 / 10 / 1 \mathrm{w} / \mathrm{w} \mathrm{iPP} / \mathrm{wax} / \mathrm{Ag}$

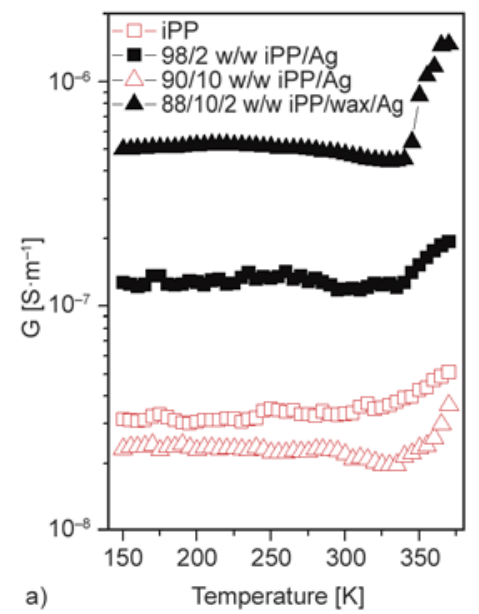

the iPP/Ag composites at $4 \mathrm{wt} \% \mathrm{Ag}$, and this confirms our previous observation that the silver particles were more concentrated in the wax phase than in the iPP phase. This is clear from the TEM photo of an iPP/wax/Ag composite (Figure 11), which clearly indicates the existence of chain-like structures of Ag particles in the samples, and which should have contributed to an increase in electrical conductivity at low concentrations of silver nanoparticles. Figure 12 presents the temperature dependence of the dielectric properties of $\mathrm{iPP}$ and $\mathrm{iPP} /$ wax composites with $2 \mathrm{wt} \% \mathrm{Ag}$ nanoparticles at a frequency of $172 \mathrm{kHz}$. The conductance of the samples decreased after the addition of $10 \mathrm{wt} \%$ wax, which can be attributed to the presence of the interface between the immiscible wax and iPP. When Ag particles are present the conductance of the $\mathrm{iPP} / \mathrm{Ag}$ sample is higher than those of pure iPP and the iPP/wax sample. In the iPP/Ag sample, the Ag particles acted as nucleation centers, as discussed in section 3.1, and are therefore in intimate contact with the iPP crystallites. The iPP crystallites in contact with the $\mathrm{Ag}$ particles seem to have a strong influence on the conductivity of the nanocomposites. In the presence of both wax and $\mathrm{Ag}$, the conductance is even higher. When wax is present in the $\mathrm{iPP} / \mathrm{Ag}$ sample, the $\mathrm{Ag}$ particles are no longer in contact with iPP crystals, but covered by the more crystalline wax which further improves the electrical conductivity. The conductance of $\mathrm{iPP}$ and $\mathrm{iPP} / \mathrm{Ag}$ remained nearly constant at lower temperatures, but slowly increased at higher temperatures. When wax was present, the conductance of $\mathrm{iPP} /$ wax and $\mathrm{iPP} / \mathrm{wax} / \mathrm{Ag}$ also remained nearly constant at lower temperatures, but decreased at about $325 \mathrm{~K}$, followed by a significant increase

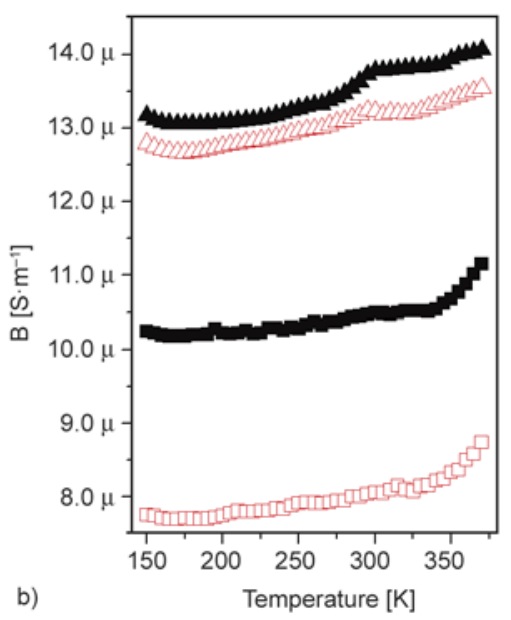

Figure 12. Temperature dependence of the dielectric properties of the composites with $2 \mathrm{wt} \% \mathrm{Ag}$ nanoparticles at $172 \mathrm{kHz}$ 
in conductivity. This indicates that the presence of the more crystalline wax had a strong influence on the conductivity.

The susceptance showed different behaviour from that of the conductance in the presence of wax (Figure 12b). The susceptance of $\mathrm{iPP} /$ wax is higher than those of both pure iPP and iPP/Ag. Both iPP and wax are non-polar materials, but excellent electric insulators that can be polarized by the applied electric field. When an electric field is applied to iPP/wax, the electrons do not move through the blend as they would have done in a conductor, but move only slightly, causing a small dielectric polarization because wax more easily responds to polarization than iPP. When both wax and Ag were present, the susceptance of iPP in iPP/wax/Ag sample was higher than those of $\mathrm{iPP} / \mathrm{Ag}$ and $\mathrm{iPP} / \mathrm{wax}$. This shows that in the presence of both the conductor and wax, when an external electric field was applied, the electrons moved in such a way that they were free to polarize the conductor. The wax-covered Ag particles easily responded to the polarization, and the susceptance was therefore very large. When the susceptance of $\mathrm{iPP} /$ wax and $\mathrm{iPP} / \mathrm{wax} / \mathrm{Ag}$ are compared, the wax slightly improved the polarity of iPP, but the wax-covered Ag particles significantly improved its polarity. The susceptance is the ratio of polarization to the applied electric field, and the changes observed in the susceptance of the composites are the result of the changes in polarization.

In order to study the effect of Ag particles on the conductivity of iPP and the iPP/wax blend, the relative increase in admittance $(\Delta Y(f, T)=$ $\left.100 \cdot\left(Y_{\mathrm{pol}+\mathrm{Ag}}-Y_{\mathrm{pol}}\right) / Y_{\mathrm{pol}}\right)$ of iPP and iPP/wax due to the presence of $2 \mathrm{wt} \% \mathrm{Ag}$ was determined. The results are presented in Figures 13 and 14. A transition which is associated with the $\gamma$-relaxation appeared at about $173 \mathrm{~K}$ in both composites. It has been previously reported that the $\gamma$-relaxation of iPP appears between 150 and $230 \mathrm{~K}$, and this relaxation is usually associated with the local motions in the amorphous phase [24]. The difference in conductivity between iPP and iPP/Ag slightly increases with increasing temperature up to this temperature, followed by a decrease at higher temperatures. The non-polar iPP usually shows a $\gamma$-relaxation, but the introduction of polar groups had previously made the $\gamma$-relaxation peak disappear [25]. The observed $\gamma$ relaxation in $\mathrm{PP} / \mathrm{Ag}$ therefore confirms that the $\mathrm{Ag}$ particles did not improve the polarity of iPP. The

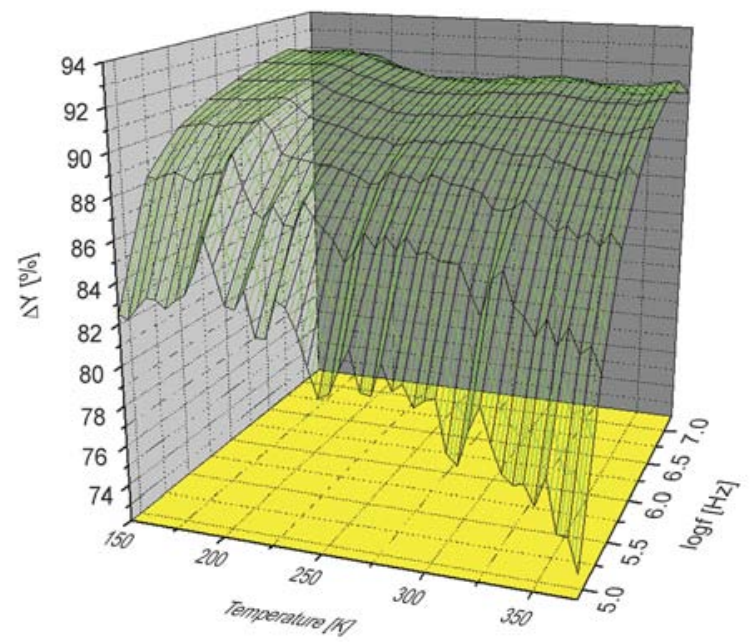

Figure 13. Relative increase of admittance due to the presence of $2 \mathrm{wt} \% \mathrm{Ag}$ nanoparticles in iPP as function of temperature and frequency

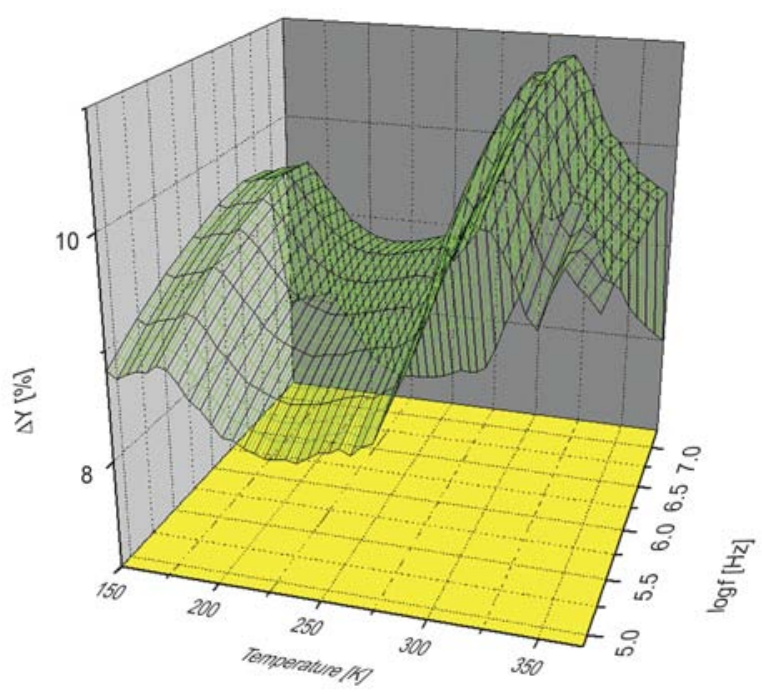

Figure 14. Relative increase in admittance due to the presence of $2 \mathrm{wt} \% \mathrm{Ag}$ nanoparticles in 90/10 w/w $\mathrm{iPP} /$ wax as function of temperature and frequency

iPP/wax/Ag sample has two transitions associated with the $\gamma$-transition and the softening of wax, respectively at about 173 and $300 \mathrm{~K}$ (Figure 14). Although the conductivity of $\mathrm{iPP} / \mathrm{wax}$ and $\mathrm{iPP} / \mathrm{wax} / \mathrm{Ag}$ increased with increasing temperature (Figure 12), the difference in their admittance increased up to the $\gamma$-transition of iPP, followed by a decrease in admittance at temperatures above the $\gamma$-transition. Again, the difference in admittance $(\Delta Y)$ slightly increased with increasing temperature up to the onset of wax softening, followed by a significant increase up to wax melting. At temperatures above the melting of wax the admittance of iPP/wax/Ag more slowly increased than that of $\mathrm{PP} / \mathrm{Ag}$, probably because of 
the destruction of the semi-conductive paths during the softening of the wax. The difference in admittance only slightly changed during the softening of iPP, but significantly changed during the softening of the wax, which confirms that the Ag particles were mostly dispersed in the wax phase.

\section{Conclusions}

The purpose of the study was to correlate the morphologies of quenched and slowly cooled $\mathrm{PP} / \mathrm{Ag}$ and $\mathrm{iPP} / \mathrm{wax} / \mathrm{Ag}$ samples with the thermal and dynamic mechanical properties, as well as the thermal and electrical conductivities. At low contents the Ag nanoparticles were concentrated at the growth centres of the iPP spherulites in the iPP/Ag nanocomposites and formed nucleation centres for the crystallization of iPP, while wax crystallized separately from iPP and influenced the growth of the iPP spherulites by acting as a diluent. The Ag nanoparticles had a larger affinity for wax and were no longer observed at the growth centres of the iPP spherulites, and they had little influence on the mobility of the iPP chains and on its crystallinity. The wax-covered Ag particles significantly improved the thermal and electrical conductivities of the samples, but reduced the modulus.

With increasing Ag content in $\mathrm{PP} / \mathrm{Ag}$, the nanoparticles remained at the growth centres of the iPP spherulites, but the filler was not so well dispersed and the extent of the agglomeration increased. In iPP/wax/Ag with higher filler contents, Ag agglomerates were also observed at the growth centres of the iPP spherulites, but they had little influence on the crystallinites of iPP in all the samples. The thermal conductivities of both the iPP and iPP/wax based samples increased with increasing $\mathrm{Ag}$ content, but leveled off at higher filler contents, while the electrical conductivities continued increasing with increasing filler contents. In the iPP/wax blend the melting enthalpies of iPP increased with an increase in wax content, and the highly crystalline wax increased the stiffness of the quenched samples, but it had a softening effect on the slowly cooled samples. The presence of wax increased the thermal conductivities, but decreased the electrical conductivities of the blends.

Both the quenching and slow cooling treatments had an influence on the crystallinities, and the associated properties, of the samples. In summary, the highly crystalline wax improved the thermal heat transport of both the quenched and slowly cooled samples, but decreased the electrical conductivity because of the immiscibility of iPP and wax. The presence of Ag in iPP/wax significantly improved the thermal and electrical conductivities of both the quenched and slowly cooled samples, because of the coverage of the Ag particles by the highly crystalline wax.

\section{Acknowledgements}

The National Research Foundation and Sasol Inzalo in South Africa financially supported the research, which was also supported in part by the Ministry of Education and Science, Republic of Serbia (Project No. 171029).

\section{References}

[1] Zhang K., Han B., Yu X.: Electrically conductive carbon nanofiber/paraffin wax composites for electric thermal storage. Energy Conversion and Management, 64, 62-67 (2012).

DOI: $10.1016 /$ j.enconman.2012.06.021

[2] Kim S., Drzal L. T.: High latent heat storage and high thermal conductive phase change materials using exfoliated graphite nanoplatelets. Solar Energy Materials and Solar Cells, 93, 136-142 (2009). DOI: $10.1016 /$ j.solmat.2008.09.010

[3] Xiang J., Drzal L. T.: Investigation of exfoliated graphite nanoplatelets $(x \mathrm{GnP})$ in improving thermal conductivity of paraffin wax-based phase change material. Solar Energy Materials and Solar Cells, 95, 1811-1818 (2011)

DOI: 10.1016/j.solmat.2011.01.048

[4] Koning C., Van Duin M., Pagnoulle C., Jerome R.: Strategies for compatibilization of polymer blends. Progress in Polymer Science, 23, 707-757 (1998). DOI: $10.1016 / \mathrm{S} 0079-6700(97) 00054-3$

[5] Xiao M., Feng B., Gong K.: Preparation and performance of shape stabilized phase change thermal storage materials with high thermal conductivity. Energy Conversion and Management, 43, 103-108 (2002).

DOI: $10.1016 / \mathrm{S} 0196-8904(01) 00010-3$

[6] Mills A., Farid M., Selman J. R., Al-Hallaj S.: Thermal conductivity enhancement of phase change materials using a graphite matrix. Applied Thermal Engineering, 26, 1652-1661 (2006).

DOI: 10.1016/j.applthermaleng.2005.11.022

[7] Sari A., Karaipekli A.: Thermal conductivity and latent heat thermal energy storage characteristics of paraffin/ expanded graphite composite as phase change material. Applied Thermal Engineering, 27, 1271-1277 (2007).

DOI: 10.1016/j.applthermaleng.2006.11.004 
[8] Fernandes D., Pitié F., Cáceres G., Baeyens J.: Thermal energy storage: 'How previous findings determine current research priorities'. Energy, 39, 246-257 (2012). DOI: $10.1016 /$ j.energy.2012.01.024

[9] Tadjarodi A., Zabihi F.: Thermal conductivity studies of novel nanofluids based on metallic silver decorated mesoporous silica nanoparticles. Materials Research Bulletin, 48, 4150-4156 (2013).

DOI: 10.1016/j.materresbull.2013.06.043

[10] Mngomezulu M. E., Luyt A. S., Krupa I.: Structure and properties of phase-change materials based on highdensity polyethylene, hard Fischer-Tropsch paraffin wax, and wood flour. Polymer Composites, 32, 11551163 (2011).

DOI: $10.1002 / p c .21134$

[11] Mngomezulu M. E., Luyt A. S., Krupa I.: Structure and properties of phase change materials based on HDPE, soft Fischer-Tropsch paraffin wax, and wood flour. Journal of Applied Polymer Science, 118, 15411551 (2010).

DOI: 10.1002/app.32521

[12] Molefi J. A., Luyt A. S., Krupa I.: Investigation of thermally conducting phase-change materials based on polyethylene/wax blends filled with copper particles. Journal of Applied Polymer Science, 116, 1766-1774 (2010).

DOI: 10.1002/app.31653

[13] Mhike W., Focke W. W., Mofokeng J. P., Luyt A. S.: Thermally conductive phase-change materials for energy storage based on low-density polyethylene, soft Fischer-Tropsch wax and graphite. Thermochimica Acta, 527, 75-82 (2012). DOI: $10.1016 /$ j.tca.2011.10.008

[14] Sari A.: Form-stable paraffin/high density polyethylene composites as solid-liquid phase change material for thermal energy storage: Preparation and thermal properties. Energy Conversion and Management, 45, 2033-2042 (2004).

DOI: 10.1016/j.enconman.2003.10.022

[15] Zhang L., Zhu J., Zhou W., Wang J., Wang Y.: Thermal and electrical conductivity enhancement of graphite nanoplatelets on form-stable polyethylene glycol/polymethyl methacrylate composite phase change materials. Energy, 39, 294-302 (2012). DOI: $10.1016 /$ j.energy.2012.01.011

[16] Di Lorenzo M. L.: Spherulite growth rates in binary polymer blends. Progress in Polymer Science, 28, 663689 (2003).

DOI: 10.1016/S0079-6700(02)00035-7
[17] Krupa I., Luyt A. S.: Thermal properties of polypropylene/wax blends. Thermochimica Acta, 372, 137-141 (2001).

DOI: 10.1016/s0040-6031(01)00450-6

[18] Krupa I., Miková G., Luyt A. S.: Polypropylene as a potential matrix for the creation of shape stabilized phase change materials. European Polymer Journal, 43, 895-907 (2007).

DOI: 10.1016/j.eurpolymj.2006.12.019

[19] Menczel J. D., Prime R. B.: Thermal analysis of polymers. Fundamentals and applications. Wiley, New Jersey (2009).

[20] Pandis C., Logakis E., Kyritsis A., Pissis P., Vodnik V. V., Džunuzović E., Nedeljković J. M., Djoković V., Hernández J. C. R., Ribelles J. L. G.: Glass transition and polymer dynamics in silver/poly(methyl methacrylate) nanocomposites. European Polymer Journal, 47, 15141525 (2011).

DOI: 10.1016/j.eurpolymj.2011.06.001

[21] Vladimirov V., Betchev C., Vassiliou A., Papageorgiou G., Bikiaris D.: Dynamic mechanical and morphological studies of isotactic polypropylene/fumed silica nanocomposites with enhanced gas barrier properties. Composites Science and Technology, 66, 2935-2944 (2006). DOI: 10.1016/j.compscitech.2006.02.010

[22] Song Y. S., Youn J. R.: Influence of dispersion states of carbon nanotubes on physical properties of epoxy nanocomposites. Carbon, 43, 1378-1385 (2005). DOI: 10.1016/j.carbon.2005.01.007

[23] Krupa I., Novák I., Chodák I.: Electrically and thermally conductive polyethylene/graphite composites and their mechanical properties. Synthetic Metals, 145, 245-252 (2004).

DOI: 10.1016/j.synthmet.2004.05.007

[24] Suljovrujic E., Trifunovic S., Milicevic D.: The influence of gamma radiation on the dielectric relaxation behaviour of isotactic polypropylene: The $\alpha$ relaxation. Polymer Degradation and Stability, 95, 164-171 (2010).

DOI: $10.1016 /$ j.polymdegradstab.2009.11.034

[25] Suljovrujic E.: Complete relaxation map of polypropylene: radiation-induced modification as dielectric probe. Polymer Bulletin, 68, 2033-2047 (2012).

DOI: $10.1007 / \mathrm{s} 00289-012-0714-1$ 